\title{
Perfil Acadêmico dos Professores de Bioética nos Cursos de Pós-graduação no Brasil
}

\author{
The Academic Background of Bioethics \\ Professors in Graduate Studies Courses in \\ Brazil
}

Antonio Macena de Figueiredo

\section{- Ensino \\ - Bioética \\ - Docentes}

PALAVRAS-CHAVE
Recebido em: 01/07/2010

Aprovado em: 11/09/2010

REVISTA BRASILEIRA DE EDUCAÇ̃̃o MÉDICA

\section{RESUMO}

Este trabalho apresenta a sintese dos resultados de uma pesquisa documental sobre o ensino de Bioética na pós-graduação da área da saúde. Seu objetivo principal é caracterizar o perfil acadêmico dos professores desse curso. Para tanto, foi mapeado o perfil acadêmico de professores das disciplinas relacionadas com a Bioética de 163 cursos reconhecidos pela CAPES. Por meio da identificação dos docentes nos programas das disciplinas, efetuou-se uma pesquisa nos currículos disponíveis na Plataforma Lattes do CNPq. Devido à ausência de registros e tendo-se excluído aqueles que aparecem mais de uma vez em outras disciplinas, só foi possível analisar os currículos de 96 professores. Desses, 58 $(60,4 \%)$ eram do sexo masculino, sendo 45 (46,9\%) da área médica; 51 (53,1\%) de outras 12 áreas acadêmicas; 36 (37,5\%) têm duas ou mais pós-graduações; 2 (2,08\%) são graduados em Filosofia; 1 $(1,04 \%)$ em Linguística; $83(86,47 \%)$ dos currículos não registram formação específica em cursos lato ou stricto sensu em Filosofia, Ética e Bioética; 16 (n=16,7\%) integram Comitês de Ética e em apenas $5(5,2 \%)$ constam que já participaram desse tipo de comitê. O estudo evidenciou que o maior desafio é vencer a carência de profissionais qualificados para o ensino da Bioética em pós-graduação no País.

This article summarizes the results of a document survey on the teaching of Bioethics in graduate studies courses in the health field, specifically related to one of its objectives: to characterize the professors' academic background. The academic background was mapped for Bioethics professors from 163 courses accredited by CAPES, the Brazilian Federal agency for graduate studies. By identifying the faculty members through the course programs, a survey of their resumés was performed in the CNPq Lattes database. Due to lack of records and exclusion of names that appeared more than once in other courses, it was only possible to analyze the resumés of 96 professors. Of these, 58 (60.4\%) were male, $45(46.9 \%)$ were from the medical field, 51 (53.1\%) from 12 other academic fields, 36 (37.5\%) had two or more graduate degrees, and 2 (2.08\%) had graduated in philosophy and 1 (1.04\%) in linguistics. In $83(86.47 \%)$ of the resumés, there was no record of specific training in courses on Philosophy, Ethics, or Bioethics. Sixteen $16(n=16.7 \%)$ were formal members of Institutional Review Boards or Ethics Committees, but only 5 (5.2\%) had already participated actively. The study showed that the greatest challenge is to overcome the lack of qualified professionals for teaching Bioethics in Brazil's graduate courses. 


\section{INTRODUÇÃO}

A Bioética surgiu em 1970 nos Estados Unidos e, nessa década, foi incorporada como campo de aprendizado nas universidades das Ciências Biomédicas estadunidenses ${ }^{1}$, difundindo-se para a Europa nos anos 1980; no início dos anos 1990, para a Ásia; e, a partir de meados da década de 1990, para os países em desenvolvimento ${ }^{2}$. No Brasil, sua institucionalização é considerada tardia ${ }^{3}$, pois conta com aproximadamente 20 anos de atividades acadêmicas, porém, atualmente, são inúmeros os cursos de pós-graduação que oferecem essa disciplina.

Uma das primeiras iniciativas de inclusão dessa matéria na qualificação profissional aconteceu no curso de pós-graduação na área de Medicina da Pontifícia Universidade Católica (PUC) da cidade de Porto Alegre, em 1988. Na época, foi criado um programa voltado ara a preparação de profissionais da área médica, cujo objetivo era formar profissionais para resolverem dilemas e/ou conflitos éticos ${ }^{4}$.

Como disciplina autônoma, a Bioética vem sendo incluída na estrutura curricular de diversos cursos e inserida como linha de pesquisa em vários programas de pós-graduação lato sensu e stricto sensu ${ }^{5}$. Dessa maneira, nos últimos anos, inúmeras atividades relacionadas com a Bioética nas áreas de assistência, ensino e pesquisa vêm sendo desenvolvidas.

No entanto, não se tem conhecimento sobre o número de disciplinas que atualmente são oferecidas nas centenas de cursos de mestrado e doutorado reconhecidos pela CAPES no País, muito menos qual o perfil acadêmico dos profissionais envolvidos no seu ensino. Em uma recente pesquisa realizada pelo autor no doutorado pela Cátedra da UNESCO em Bioética na Universidade de Brasília (UnB), em 2009, sob a orientação do Prof. Dr. Volnei Garrafa, foram analisadas as grades curriculares de 691 cursos de mestrado e doutorado reconhecidos pela CAPES ${ }^{5}$ da grande área das Ciências da Saúde CAPES.

Desse universo, foram identificados 163 (23,6\%) cursos com disciplinas cujo o termo bioética se encontrava incorporado ao nome da matéria, dos quais 157 ofereciam uma única disciplina e 6 mais de uma matéria dedicada a esse tema. Destas 6 matérias, 4 contam como 2 disciplinas e, em outros 2 cursos, 3 matérias, devido às suas cargas horárias distintas, contabilizam seis disciplinas diferentes. Isso dá um total de 171 disciplinas na estrutura curricular desses $\operatorname{cursos}^{5}$ que englobam a Bioética.

Neste artigo, apresenta-se apenas parte dos resultados da pesquisa. Aqui se busca especificamente caracterizar o perfil acadêmico dos professores responsáveis pelos ensinamentos de Bioética nessas 171 disciplinas existentes nos cursos de pós-graduação stricto sensu na área da saúde.

\section{MÉTODO}

Foi realizada uma pesquisa documental, exploratória e descritiva com abordagens quantitativa e qualitativa, por meio da qual se buscou conhecer o perfil acadêmico dos professores que lecionam disciplinas relacionadas à Bioética nos cursos de pós-graduação stricto sensu na área das Ciências da Saúde.

Em uma primeira etapa, buscou-se identificar, entre os 691 cursos de mestrado e doutorado avaliados e reconhecidos pela CAPES no triênio 2004-2006 cujos resultados foram publicados em abril de 2008, aqueles que incluíram a Bioética como disciplina autonôma na grade curricular.

Foi efetuada uma pesquisa no endereço eletrônico da CAPES, <http://www.capes.gov.br/cursos-recomendados>, a partir do acesso ao menu "cursos reconhecidos e recomendados" no período de julho a agosto de 2008. Depois, procedeu-se uma pesquisa nas grades curriculares com objetivo de verificar aqueles cursos que continham a disciplina de Bioética. Consideraram-se disciplinas relacionadas com a Bioética aquelas em que o termo encontrava-se incluído no título da matéria.

A partir da análise dos programas das disciplinas dos cursos de mestrado e doutorado na grande área da saúde (Educação Física, Enfermagem, Farmácia, Fisioterapia e Terapia Ocupacional, Fonoaudiologia, Medicina I, II e III, Nutrição, Odontologia e Saúde Coletiva), foram identificados os nomes dos professores que lecionam as respectivas disciplinas.

Posteriormente, foi efetuada uma consulta aos currículos dos docentes na Plataforma Lattes, no portal do Conselho Nacional de Desenvolvimento Científico e Tecnológico (CNPq) $<$ http://www.cnpq.br $>$, com o propósito de caracterizar o perfil acadêmico dos professores considerando os seguintes elementos: sexo; formação universitária; titulação acadêmica (doutorado, livre-docência e pós-doutorado) nas áreas de concentração em Filosofia, Ética e Bioética; formação específica em Bioética em nível de mestrado acadêmico ou especialização; ano de conclusão da pós-graduação; e participação em Comitês de Ética em Pesquisa.

Considerando que o mestrado é o primeiro nível de qualificação acadêmica e, por conseguinte, o doutorado constitui o requisito exigido para lecionar na pós-graduação stricto sensu, optou-se por pesquisar apenas os mestres que possuíam qualificação acadêmica na área de concentração em Bioética. Em relação aos professores com título de doutor, a investigação envolveu todas as áreas de concentração, além das específicas em Filosofia, Ética e Bioética.

\section{RESULTADOS}

É oportuno salientar que, na época da pesquisa, seis currículos não estavam atualizados e, por não conter os nomes dos pro- 
fessores em 41 disciplinas, só foi possível levantar o perfil dos docentes de 130 (76,0\%) matérias.

Desse total, excluídos os nomes daqueles que apareciam mais de uma vez em outras disciplinas, seja compartilhando as atividades com outros docentes ou assumindo a responsabilidade pelo ensino isoladamente, restou para análise o currículo de 96 professores.

De início, um dado chamou muito atenção: ao confrontar os nomes dos docentes, constatou-se que um grupo de 12 professores aparecem como responsáveis, sozinhos, por 49 disciplinas em diversos cursos de mestrado e doutorado. Além disso, em 55,0\% (94) das disciplinas, o ensino é conduzido por apenas 1 professor. Isso evidencia que há uma sobrecarga de trabalho assumida por um pequeno grupo de docentes, sendo, portanto, um indicativo de que há escassez de docentes qualificados para lecionar essa matéria.

Quanto às características do perfil profissional dos docentes, o primeiro elemento a ser analisado refere-se ao gênero. De acordo com o gráfico 1, observa-se que a maioria é do sexo masculino ( $\mathrm{n}=58 ; 60,4 \%)$, apesar do número expressivo de professoras atuando na pós-graduação stricto sensu ( $\mathrm{n}=38,39,4 \%)$.

\section{GRÁFICO 1}

Perfil Acadêmico dos Professores DAS Disciplinas Relacionadas com a Bioética de Acordo com o Sexo — 2008

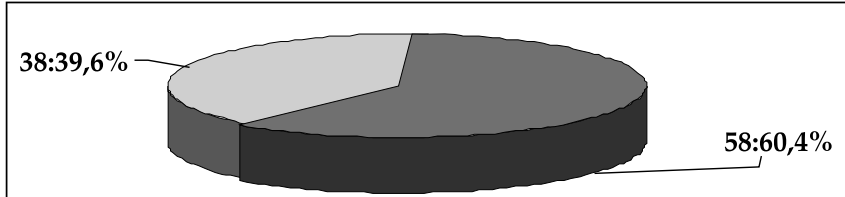

$\square$ Feminino

$\square$ Masculino

Fonte: $\quad$ http://www.capes.gov.br/svsliscao/recomendados.html. Identificação dos profes sores responsáveis pelo ensino da bioética com base nos programas das disciplinas.

Quanto à formação universitária, verificou-se que 45 (46,88\%) professores têm formação na área da Medicina, seguidos de 19 (19,8\%) profissionais da Odontologia, 10 (10,42\%) da Enfermagem e, em quarto lugar, os farmacêuticos que são 3 $(3,13 \%)$ ao todo. Os docentes das nove áreas restantes restringiram-se a um número pouco expressivo, 19 (19,75\%), como demonstra a tabela 1.

Apesar de ser pouco expressiva a atuação dos docentes provenientes das áreas não médicas, é importante reconhecer a multidisciplinaridade da formação dos profissionais envolvidos com o ensino da Bioética. Mesmo em condições minoritárias, constatou-se que os professores responsáveis pelas
TABELA 1 - PERFIL ACADÊMICO DOS PROFESSORES RESPONSAYEIS PELA DISCIPL NA DE BIOÉTICA DE ACORDO OOM A FORMACÄO UNIVERSITARIA F ANO DE CONCLU-

\begin{tabular}{|c|c|c|c|c|c|}
\hline Graduaçăo & $\mathrm{N}^{0}$ & $\%$ & Ano conclus ão do curso $\phi^{1,2}$ & $\mathrm{~N}^{*}$ & $\%$ \\
\hline 1. Bialogia & 2 & 2,08 & \multirow{3}{*}{$19501-1955$} & \multirow{3}{*}{1} & \multirow{3}{*}{1,04} \\
\hline 2.Direito & 1 & 1,04 & & & \\
\hline 3.Enfermagem & 10 & 10,42 & & & \\
\hline 4.Farmácia & 3 & 3,13 & \multirow[t]{2}{*}{$19551-1960$} & \multirow{2}{*}{2} & \multirow{2}{*}{2,08} \\
\hline 5.Filosofia & 2 & 2,08 & & & \\
\hline G.Fonoaudiologia & 1 & 1,04 & \multirow{3}{*}{$19601-1965$} & \multirow{3}{*}{6} & \multirow{3}{*}{6,25} \\
\hline 7.Linguística & 1 & 1,04 & & & \\
\hline 8.Nutriçâ̆o & 1 & 1,04 & & & \\
\hline 9.Medicina & 45 & 46,89 & \multirow[t]{2}{*}{1965 I- 1970} & \multirow[t]{2}{*}{10} & \multirow[t]{2}{*}{10,42} \\
\hline 10.Medicina veterinắría & 1 & 1,04 & & & \\
\hline 11.0dontologia & 19 & 19,80 & \multirow[t]{2}{*}{$1970 \mid-1975$} & \multirow[t]{2}{*}{19} & \multirow[t]{2}{*}{19,70} \\
\hline 12.Química & 1 & 1,04 & & & \\
\hline 13.Psicolagia & 1 & 1,04 & \multirow[t]{2}{*}{$1975 I-1980$} & \multirow[t]{2}{*}{17} & \multirow[t]{2}{*}{17,71} \\
\hline Duas graduaçöes & & & & & \\
\hline $\begin{array}{l}\text { 1.1.1 Pedagogia } \\
\text { 1.2 Enfermagem }\end{array}$ & 1 & 1,04 & \multirow[t]{2}{*}{$19801-1965$} & \multirow[t]{2}{*}{20} & 20,8 \\
\hline $\begin{array}{l}\text { 2.2.1 Filosofia } \\
2.2 \text { Enfermagem }\end{array}$ & 1 & 1,04 & & & \multirow[t]{2}{*}{9,38} \\
\hline $\begin{array}{l}\text { 3.3.1 Filosofia } \\
\text { 3.2 Artes Plásticas }\end{array}$ & 1 & 1,04 & \multirow{2}{*}{$1990 \mid-1995$} & 9 & \\
\hline $\begin{array}{l}\text { 4.4.1 Educaçä́ Física } \\
4.2 \text { Fisioterapia }\end{array}$ & 1 & 1,04 & & , & 0,29 \\
\hline $\begin{array}{l}5.5 .1 \text { Direito } \\
5.2 \text { Odontologia }\end{array}$ & 3 & 3,13 & \multirow[t]{2}{*}{$1995 \mathrm{I}-2000$} & \multirow[t]{2}{*}{5} & \multirow[t]{2}{*}{5,21} \\
\hline $\begin{array}{l}\text { 6.6.1 Direito } \\
6.2 \text { Medicina }\end{array}$ & 1 & 1,04 & & & \\
\hline Total & 96 & $100 \%$ & & 96 & $100 \%$ \\
\hline
\end{tabular}

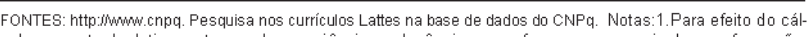
culo percentual relativo a tempo de experiência na docência, as professores com mais de uma formaçáa no de cancluä̃o do curso são indenendentes.

disciplinas relacionadas com a Bioética advêm de 13 áreas distintas. Entretanto, essa aparente característica não significa compartilhamento na prática, pois observa-se que o ensino ainda é conduzido por um único professor na maioria das diciplinas (tabela 2).

\section{TABELA 2}

Distribuição dos Professores de Acordo com as Disciplinas Relacionadas com a Bioética - 2008

\begin{tabular}{ccc}
\hline $\begin{array}{c}\text { Distribuição da } \\
\text { disciplina por } \\
\text { professor }\end{array}$ & Frequência & $\%$ \\
\hline 1 & 94 & 55,00 \\
2 & 28 & 16,40 \\
3 & 3 & 1,70 \\
4 & 5 & 2,90 \\
Sem registro & 41 & 24,00 \\
\hline Total & 171 & 100,00 \\
\hline
\end{tabular}

Fonte: http:/ / capes.gov.br/cursos-recomendados. Informações extraídas dos programas das disciplinas de Bioética.

Em relação aos profissionais com mais de uma formação universitária, verifica-se que somente $8(8,33 \%)$ docentes possuem duas graduações. Considerando que seria praticamente impossível ser um expert em diversas áreas do conhecimento, supõe-se, em tese, que aqueles que possuem mais de uma 
formação, dominando outra área do conhecimento, poderá contribuir para o redimensionamento dos debates entre essas especialidades e, por consequência, valorizar outros ângulos de visão na análise dos dilemas e/ou conflitos morais.

Quanto ao tempo de conclusão da formação acadêmica, este variou entre 50 (um docente) e 12 anos (cinco docentes). No entanto, constatou-se que cerca de $78,13 \%$ dos docentes têm entre 18 a 38 anos de experiência profissional, uma vez que concluíram a graduação entre 1970 e 1990 (tabela 1). Essa evidência sugere que um número significativo de professores possui sólida experiência no ensino da Ética, o que se verfica especialmente entre os profissionais da área médica.

Esse dado deve ser interpretado positivamente, porque a experiência no magistério superior é atributo essencial à reflexão do processo pedagógico de ensino. Não é sem razão que, em uma recente pesquisa sobre o ensino da Ética e Bioética nos cursos de Enfermagem, Medicina e Odontologia em Manaus, os atributos mais citados pelos docentes entrevistados relacionados ao bom professor de Ética foram vivência e experiência profissional ${ }^{6}$.

Quanto ao perfil por área de concentração, observa-se que o maior número de docentes com doutorado é também entre os da área médica, 22 (22,92\%) ao todo. Na ordem, aparecem os profissionais com qualificação nas áreas de concentração da Odontologia 10 (10,42\%), Enfermagem 9 (9,38\%), Genética 3 (3,13\%), Nutrição e Saúde Coletiva $2(2,08 \%)$. Quanto às demais áreas acadêmicas, cerca de $10(10,42 \%)$ representam os outros campos, excluindo aqueles com mais de uma pós-graduação (tabela 3).

Em atinência à titulação máxima, apenas 2 (2,08\%) docentes possuem o título de livre-docência isoladamente. Caso se considere que esses profissionais pertencem a um grupo de professores com considerável experiência no magistério superior, provavelmente, isso se deve ao fato de que, antes de 1972, os professores podiam ser submetidos à prova de habilitação de livre-docência sem ter o título de doutor.

Por sua vez, existe um número expressivo de professores com mais de uma pós-graduação, 36 (37,50\%) possuem duas ou mais titulações, sendo $27(28,12 \%)$ com duas pós-graduações (doutorado, pós-doutorado ou livre-docência) e com três ou mais foram identificados 9 (9,37\%) professores (tabela 3). Esses profissionais, em sua maioria, são também da área médica. Igualmente, demonstra-se a prevalência de professores advindos da área médica com titulação acadêmica máxima.

Quanto ao tempo de obtenção da titulação acadêmica, constatou-se que $25(26,04 \%)$ professores obtiveram a qualificação antes da década de 1990; 43 (44,80\%) entre 1991 e 2000. Portanto, possuem cerca de 8 anos de experiência acadêmica. Também observou-se que $26(27,08 \%)$ concluíram a qualificação acadêmica entre de 2001 e 2005; e apenas 2 (2,08\%) recentemente (tabela 3).

\begin{tabular}{|c|c|c|c|c|c|}
\hline Titulaçãa - & $\mathrm{N}^{0}$ & $\%$ & Ano conclusão do curso 2,3 & $\mathrm{~N}^{0}$ & $\%$ \\
\hline \multicolumn{6}{|c|}{ 1.Doutorado por área de concentraçăa ${ }^{1}$} \\
\hline 1. Biaquimica & 1 & 1,04 & \multirow{3}{*}{$1955 \mid-1960$} & \multirow{3}{*}{1} & \multirow{3}{*}{1,04} \\
\hline 2. Educ açẫo & 1 & 1,04 & & & \\
\hline 3.Eniermagem & $\mathrm{g}$ & 9.37 & & & \\
\hline 4.Farmacologia & 1 & 1,04 & \multirow{3}{*}{$19601-1965$} & \multirow{3}{*}{1} & \multirow{3}{*}{1,04} \\
\hline 5.Fisioterapia/Terapia Qcupacional & 1 & 1,04 & & & \\
\hline G. Filosonia & 1 & 1,04 & & & \\
\hline T.Fonoaudiolagia & 1 & 1,04 & \multirow{3}{*}{$19651-1970$} & \multirow{3}{*}{1} & \multirow{3}{*}{1,04} \\
\hline g.Genética & 3 & 3,13 & & & \\
\hline 9. Imunologia & 1 & 1,04 & & & \\
\hline 10.Medicina & 22 & 22,92 & \multirow{3}{*}{$19701-1975$} & \multirow[t]{3}{*}{5} & \multirow[t]{3}{*}{5,21} \\
\hline 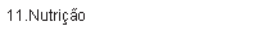 & 2 & 2,08 & & & \\
\hline 12.0dontologia & 10 & 10,42 & & & \\
\hline 13.Parasitologila & 1 & 1,04 & \multirow{3}{*}{$1975+1980$} & \multirow{3}{*}{5} & \multirow{3}{*}{5,21} \\
\hline 14.Psicologia & 1 & 1,04 & & & \\
\hline 15.5aúde coletiva & 2 & 2,00 & & & \\
\hline 16.Sociologila & 1 & 1,04 & \multirow{3}{*}{$19801-1985$} & \multirow{3}{*}{4} & \multirow{3}{*}{4,17} \\
\hline z. Liмre docência & 2 & 2,08 & & & \\
\hline 3. Mais de uma pós-graduaçăo & & & & & \\
\hline $\begin{array}{l}\text { 1. } 1.1 \text { Doutorado } \\
* 1.2 \text { Liwre dacência }\end{array}$ & 14 & 14,59 & \multirow[t]{2}{*}{$1985 \mid-1990$} & \multirow[t]{2}{*}{8} & \multirow[t]{2}{*}{8,33} \\
\hline $\begin{array}{l}\text { 2. } 2.1 \text { Doutorado } \\
=2.2 \text { Pós-doutorado }\end{array}$ & 13 & 13,56 & & & \\
\hline $\begin{array}{l}\text { 3. } 3.1 \text { Dois cursos de doutorado } \\
3.2 \text { Livre docência }\end{array}$ & 1 & 1,04 & \multirow[t]{2}{*}{$1990 \mid-1995$} & \multirow[t]{2}{*}{22} & \multirow[t]{2}{*}{22,92} \\
\hline $\begin{array}{l}\text { 4. 4.1 Doutorado } \\
\text { 4.2 Pos-doutorado }\end{array}$ & 3 & 3,13 & & & \\
\hline $\begin{array}{l}\text { 4.3 Liwre docência } \\
\text { 5. } 5.1 \text { Doutorado } \\
5.2 \text { Dois titulos de Limre docência }\end{array}$ & 1 & 1,04 & $1995 \mid-2000$ & 21 & 21,88 \\
\hline $\begin{array}{l}\text { 6. } 6.1 \text { Doutorado } \\
6.2 \text { Dois pós-douttorado } \\
6.3 \text { Lime docência }\end{array}$ & 2 & 2,08 & $20001-2005$ & 26 & 27,08 \\
\hline $\begin{array}{l}\text { 7.7.1 Dois cursos de doutorado } \\
7.2 \text { Tres pó-douttorado } \\
7.3 \text { Livire docência }\end{array}$ & 1 & 1,04 & \multirow[t]{2}{*}{$20051-$} & \multirow[t]{2}{*}{2} & \multirow[t]{2}{*}{2,08} \\
\hline $\begin{array}{l}\text { 8. 8.1 Doutorado } \\
\text { 8.2 Dois pós-doutotorado } \\
\text { 8.3 Livre docência }\end{array}$ & 1 & 1.04 & & & \\
\hline Total & 96 & $100 \%$ & & 96 & $100 \%$ \\
\hline
\end{tabular}

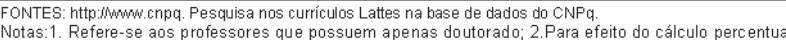
Notas:1. Refere-se aos professores que possuem apenas doutorado; 2. Para efeito do cálculo percentua
relativo ao tempo de experiência na docencia, os professores com mais de uma pós-graduaçăa conside rou-se a data de conclusa ão do primeiro curso 3 As colunas sobre a titulaçãa e ano de conclusäa do

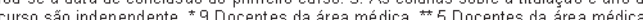

Em relação ao perfil da formação específica nas áreas de concentração em Filosofia, Ética e Bioética, constatou-se que existe um número significativo de docentes que não têm formação específica em Bioética, seja em nível de especialização, mestrado ou doutorado. Isso porque, dentre os $83(86,47 \%)$ currículos lattes analisados, não foram identificados registros relacionados à formação nessas áreas de concentração, como se constata na tabela 4 :

Importante assinalar que apenas $10(10,42 \%)$ professores concluíram os cursos de especialização, mestrado, doutorado e pós-doutorado. Ressaltando que esses especialistas possuem pós-graduação stricto sensu em outras áreas distintas da Bioética (tabela 13, item 3.1). Por sua vez, a pesquisa mostrou que $3(3,11 \%)$ docentes, por pertencerem às áreas das Ciências Humanas, obtiveram a titulação na área de concentração em Filosofia e subárea de Ética (tabela 4).

No tocante ao ano de conclusão da qualificação acadêmica, verificou-se que $5(5,21 \%)$ obtiveram a titulação entre 1996 e 2000 e $6(6,25)$, depois de 2001. Cabe evidenciar que, pelo fato de a pós-graduação stricto sensu em Bioética ser ainda recente no Brasil, 3 professores concluíram o curso fora do País (itens $1.4 ; 2.3 ; 3.2$ - tabela 4$)$. 
TABELA 4 - PERFIL ACADÉMICO DOS PROFESSORES RESPONSÁVEIS PELA DISCIPLINA DE BIOÉTICA DE ACORDO COM A FORMACAO NAS AREAS DE CONCENTRACAO EM FILO SOFIA, ÉTICA, BIOÉTICA E PARTICIPAÇAO DOS DOCENTES EM COMITÉS DE ÉTICA EM PESOUISA- 2008

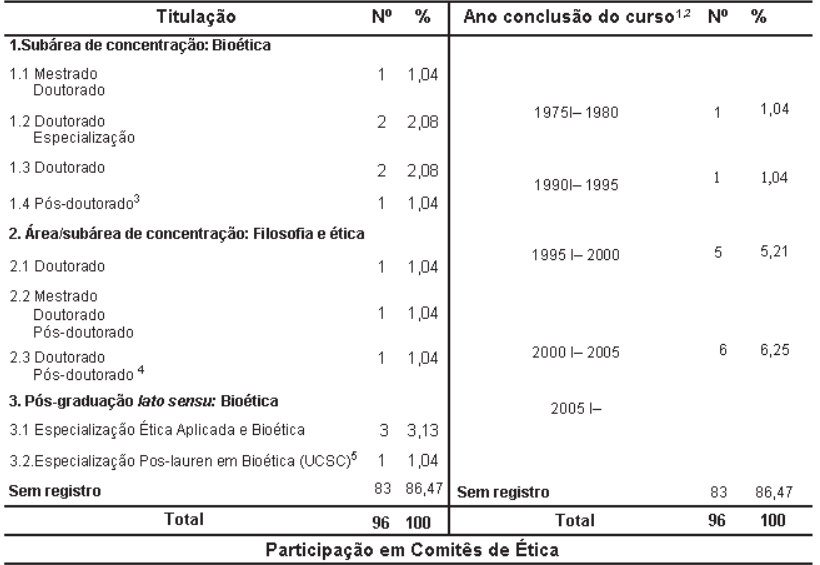

\begin{tabular}{lcc}
\hline 1. Cargo e demais informaçôes & Participação em Comitês de Etica \\
$\mathrm{N}^{*}$ & $\%$
\end{tabular}

1.Coordenador

2Foi membro

3.Meribro

4.Serti registro to curriculo Lattes

$s, 21$

FONTES: hittpinhwwicnpq. Pesquisa nos currículos Lattes na base de dados do CNPq. Nouta: 1. Para efeita do cálculo as sobre a titulacä̃ e ano de conclusän do curso sä́ independentes 3 Pós-doutorado na Universidade La Sapienzal

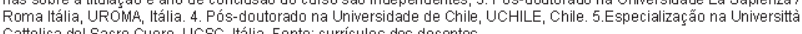

Quanto à participação dos docentes nos Comitês de Ética Institucionais, em 75 (78,13\%) currículos analisados não havia registro. Dos $21(21,87)$ documentos restantes, 9 (9,37\%) relataram ser coordenadores, 7 (7,29\%) membros efetivos e 5 $(5,21 \%)$ já atuaram de alguma forma. Isso demonstra que a grande maioria dos docentes envolvidos no ensino da Bioética na pós-graduação stricto sensu sequer possue experiência prática em Ética em Pesquisa.

Por ser a Bioética um campo de discussão no qual muitos saberes e conflitos éticos estão envolvidos, considera-se que a atuação em Comitês de Ética Institucionais é indispensável à aquisição de experiência profissional. Como é de conhecimento de todos os profissionais que atuam nesse novo campo do saber, além do conhecimento de filosofia moral e cultura humanística, a vivência e a experiência prática são atributos essenciais ao perfil pessoal e profissional daqueles que se dedicam à Bioética.

Com esses resultados, pode-se inferir que a maioria dos docentes é remanescente da área médica, tanto em relação à formação universitária (46,88\%) quanto à titulação acadêmica $(22,92 \%)$, embora se verifique a presença de professores com formação em 13 áreas de conhecimento (tabela 1) e em outras 16 especialidades (tabela 3 ).

A respeito da titulação específica na área da Filosofia, Ética ou Bioética, um grupo significativo de professores não tem formação básica ou qualificação acadêmica nessas áreas.
Da mesma forma, evidencia-se que um grupo expressivo de docentes envolvidos no ensino não tem participação ativa em Comitês de Ética em Pesquisa.

Esses dados representam uma efetiva preocupação com a quantidade das disciplinas que vêm sendo ofereceidas nos cursos de pós-graduação stricto sensu relacionadas com a Bioética, pois, além de se constatar que existe uma deficiência de profissionais qualificados para o ensino, é sabido que o acompanhamento de conflitos ou dilemas ético-morais no dia a dia dos Comitês de Ética é essencial à experiência do profissional. Isso porque se espera, sobretudo, que o professor possua vivência dos problemas ético-morais para poder discuti-los com os alunos em sala de aula.

\section{DISCUSSÃO}

Tendo o professor a árdua tarefa de conduzir o ensino e ajudar o aluno a trilhar as sendas dignas do seu proceder, depois do conhecimento do perfil acadêmico dos professores que atualmente estão envolvidos com ensino da Bioética, algumas perguntas são pertinentes: Quem são os profissionais mais apropriados para conduzir o ensino da Bioética? Que formação devem possuir? Que experiência acadêmica devem ter para lecionar em uma disciplina tão abrangente e complexa? Justifica-se estabelecer um perfil específico para o professor de Bioética?

Obviamente, são inúmeras as dificuldades de se obter respostas para esses questionamentos, sobretudo, porque nenhum curso de mestrado e doutorado ou experiência profissional será capaz de transmitir conhecimentos para trabalhar com todos os assuntos que envolvem a Bioética e conferir habilidades para lidar com as divergências de opiniões.

Sem dúvida, pela própria natureza multidisciplinar, interdisciplinar e transdisciplinar dessa área do conhecimento, alguns aspectos relacionados ao perfil dos professores requerem que se ampliem as discussões sobre que formação devem ter esses profissionais. Certamente, reconhece-se que se torna imprescindível um nível de formação mais eclético do que o de um professor de uma disciplina mais fechada como, por exemplo, Deontologia Profissional. Aqui, depara-se com o primeiro desafio, uma vez que ainda são poucos os profissionais que possuem uma formação tão ampla para discorrer sobre todos os assuntos que abrangem a Bioética e que diariamente se modificam com os novos conhecimentos ${ }^{7}$ científicos, confrontando-se frequentemente, portanto, com os valores morais já consolidados na tradição das profissões e na sociedade.

Para trabalhar com as diversas áreas do conhecimento que envolvem a Bioética e contextualizá-las com os aspectos ambientais, científicos, tecnológicos, filosóficos, sociais, culturais, valores e costumes, em que a ética e a vida interagem, são indispensáveis uma formação multidisciplinar e uma longa vivência 
acadêmica. Talvez, por essa razão, não se justifica estabelecer um perfil específico em relação a uma determinada formação universitária. Diferentemente de outras áreas, hoje, observa-se que, cada vez mais, profissionais de diversos campos de conhecimento se interessam pela Bioética. Por isso, graduados de qualquer área podem pretender atuar como professor desse tema. Ao contrário do que acontece, por exemplo, com a Ética Médica, pois, em princípio, apenas os docentes da área da Medicina seriam os mais indicados para lecionar tal disciplina.

Todavia, algumas características do perfil pessoal-acadêmico são semelhantes. Assim como se espera que o professor de Ética Médica possua vivência, conhecimento teórico e prático, formação humanística e postura ética ${ }^{8}$; para os docentes que se dedicam aos ensinamentos em Bioética, presume-se que esses atributos sejam também essenciais.

Em especial, a postura dos docentes é de fundamental importância para a aprendizagem da Ética. Obrigatoriamente, os professores devem ser exemplos, pois é o seu papel servir de modelo para os estudantes. Em uma recente pesquisa que teve como objetivo avaliar a opinião e o conhecimento de 121 (58\%) professores-médicos e 506 (50\%) estudantes de um curso de Medicina, entre os alunos, "66\% afirmaram ter observado conduta médica inadequada por parte de seus professores". 9

Outro fator a ser considerado no ensino da Bioética refere-se a uma nova orientação pedagógica no sentido de permitir a participação de outros profissionais ${ }^{10}$ que não apenas os da área médica. Assim como o ensino da Ética pode ser conduzido por teólogos, filósofos ou "eticistas"11, talvez a cooperação entre estes e sociólogos, antropólogos, advogados, médicos e outros com uma formação multidisciplinar seja bastante profícua para o ensino da Bioética. Ou seja, acredita-se que a experiência desses profissionais que tenham um contato mais estreito com outras áreas do saber e que estejam mais familiarizados com as metodologias transdisciplinares e ativas (estratégia de ensino centrada no estudante) faz com que eles sejam as pessoas mais indicadas para a docência em Bioética.

Além disso, considerando que a Bioética tem como "método de reflexão ético-filosófica aplicada a uma prática"12, torna-se indispensável para quem pretende dedicar-se a esse campo de ensino refletir sobre a necessidade de rever outras características, tais como: capacidade dialógica, ausência de preconceitos e não imposição de convicções pessoais. Nesse ponto, deve-se recordar o teor da Carta da Transdisciplinaridade, elaborada no I Congresso Mundial de Transdisciplinaridade, em 1994, que, em seu art. 13, estabelece:

A ética transdisciplinar recusa toda atitude que se negue ao diálogo e à discussão, seja qual for sua origem
— de ordem ideológica, científica, religiosa, econômica, política ou filosófica. O saber compartilhado deverá conduzir a uma compreensão compartilhada baseada no respeito absoluto das diferenças entre os seres, unidos pela vida comum sobre uma única e mesma Terra. ${ }^{13}$

Desse enunciado, pode-se afirmar que a discussão deve abranger diferentes realidades, assim como devem ser vistas por lógicas distintas. Desse modo, o professor que tentar reduzir a realidade a um único nível, regido por uma única lógica, não se situa no campo da transdisciplinaridade ${ }^{14}$.

Por isso, alguns estudiosos ponderam que a Bioética não se ensina, mas discute-se ${ }^{15}$. Assim, em sala de aula, o professor deve ser capaz de estimular a curiosidade dos alunos, procurando discutir e incentivando-os a pensar as questões diante da sua realidade, valores, princípios e normas sociais, enquadrando tudo em sua própria razão, segundo seus valores, princípios de verdade e/ou ditames de sua consciência de modo a externar uma opinião autêntica ${ }^{8}$.

O mais relevante seria, então, dotar o aluno de sensibilidade, para detectar problemas, e de aparelhamento crítico, que lhe permita analisar as situações, os princípios, as normas e os valores envolvidos, para que possa assumir posturas mais conscientes em cada caso ${ }^{8}$.

Ademais, para trabalhar nos meandros de todos os saberes ou conflitos que envolvem a Bioética se exige, ainda, bom-senso. Apesar de não se exigir um especialista para lecionar essa matéria, e por ser "uma área que envolve conflitos de interesses diversos, muitos profissionais consideram-se aptos a discutir e ensinar [Bioética]"16. Porém, adverte Garrafa ${ }^{17}$ que os estudiosos que decidiram se dedicar à Bioética devem aprender desde as primeiras lições sobre sua característica multidisciplinar. Essa afirmação denota que não basta apenas possuir conhecimentos das mais diversas áreas do saber, nem tampouco possuir o dom da retórica ou pertencer apenas a uma formação universitária. Mais que ter o domínio teórico, prático e da eloquência, é preciso ter capacidade para promover a interligação entre os saberes e ir além daquilo que já se conhece, pois esse encontro constitui a base indispensável para a discussão, em profundidade, de um mesmo objeto de estudo por várias áreas do conhecimento.

Antes de tudo, deve-se, ainda, lembrar que o professor precisa possuir os requisitos de qualquer outro profissional envolvido no magistério superior. Pondera Zabala ${ }^{18}$ que um dos objetivos do bom profissional da educação consiste em ser cada vez mais competente em seu ofício, que deve pautar sua atuação no pensamento prático, capacidade reflexiva e elaborar uma adequada análise do cotidiano de sua prática em con- 
traste com outras, visando a avaliar seu nível de conhecimento e suas estratégias de ensino.

Batista e Silva ${ }^{19}$, em recente pesquisa realizada com pós-graduandos de um curso stricto sensu de Formação Didático-Pedagógica em Saúde, enumeram alguns atributos de um "bom professor": a) capacitação didático-pedagógica; b) ética e humanismo; c) domínio do conteúdo; d) bom relacionamento professor-aluno; e) crítica e autoavaliação; f) satisfação ao ensinar; g) responsabilidade profissional; h) pesquisa e cultura geral.

Mais recentemente, em um estudo sobre o ensino da Ética e Bioética envolvendo os cursos de graduação de Medicina, Enfermagem e Odontologia em Manaus, os atributos mais citados pelos docentes entrevistados referentes ao professor de Ética foram vivência e experiência profissional. A esses atributos ainda podem ser agregados o conhecimento de Filosofia Moral e Cultura Humanística ${ }^{20}$.

Pedro Demo ${ }^{21}$, ao desenhar o perfil do professor do futuro, lembra que o aluno que se pretende "formar não é só um técnico, mas fundamentalmente um cidadão, que encontra na habilidade reconstrutiva do conhecimento seu perfil talvez mais decisivo". Por isso, não basta dar aula. É fundamental redefinir o professor como aquele que cuida da aprendizagem dos alunos com dedicação, compromisso ético e técnico, continuidade, sistematicidade, habilidade sensível e sempre renovadora de suporte ao aluno ${ }^{21}$.

Um conjunto de mudanças no cenário do ensino universitário fez com que o perfil do professor desse segmento se alterasse significativamente. Em primeiro lugar, deve-se levar em consideração o apelo da UNESCO no Relatório da Comissão Internacional sobre a Educação para o Século XXI, publicado em 1996, o qual definiu os pilares para a Educação: aprender a conhecer, isto é, adquirir os instrumentos da compreensão; aprender a fazer, para poder agir sobre o meio envolvente; aprender a viver junto, a fim de participar e cooperar com os outros em todas as atividades humanas; aprender a ser, via essencial que integra os três precedentes; $\mathrm{e}$, finalmente, aprender a participar e a antecipar ${ }^{19,22}$.

Isso significa uma mudança de atitude diante do processo ensino-aprendizagem e, dessa maneira, rompe-se o vício de que o professor "ensina" e o aluno "aprende", privilegiando-se, então, o contexto maiêutico de orientação e avaliação. Para o aluno aprender também tem de pesquisar, isto é, professores e alunos se efetivam como parceiros na construção do conhecimento. Como enfatiza Pedro Demo ${ }^{21}$, o pesquisar torna-se a tradução mais exata do saber pensar e do aprender a aprender.

Da mesma forma, deve-se recordar as orientações das Diretrizes Curriculares Nacionais relacionadas à formação básica de todos os profissionais da saúde. Por conta do novo perfil de formação dos futuros profissionais de saúde, houve uma redefinição também do perfil científico-pedagógico do professor. Para se adequar à formação generalista, humanística, crítica e reflexiva, tem-se agora o docente como facilitador e mediador do processo ensino-aprendizagem.

Especialmente na pós-graduação, docentes e discentes obrigatoriamente se tornam parceiros do processo ensino-aprendizagem. Essa participação motiva e dinamiza as relações aluno e professor. O aluno, então, "começa a ver o professor como um aliado para sua formação, e não como um obstáculo" e, assim, "sente-se igualmente responsável por aprender". ${ }^{23}$

Tais mudanças, além de fortalecerem as competências básicas para o bom desempenho da docência, irão promover as transformações necessárias à adequação do perfil do docente no que tange à realidade do processo pedagógico, exigindo-lhe, antes de tudo: competência na área de conhecimento, experiências profissionais e atualização permanente; domínio na área pedagógica, das estratégias de ensino-aprendizagem e em tecnologias de informação; exercício das dimensões técnica, estética, ética e política na docência, com compromisso na formação de profissionais responsáveis pela construção da cidadania ${ }^{23,24}$. Pode-se inferir, assim, que essas devem ser as qualidades esperadas daqueles que decidem se dedicar a ensinar Bioética.

Apesar de não existir um perfil acadêmico definido para atuar nessa área, deve-se reconhecer que, além dos vários atributos que devem possuir um bom professor, três características especialmente relacionadas ao docente de Bioética são essenciais: pessoa deliberada, mas com uma prática constante de reflexão com base em fundamentação teórica; tolerância com os princípios e valores das pessoas envolvidas em situações éticas; e prudência na tomada de decisões ${ }^{16}$.

\section{CONCLUSÃO}

Apesar da institucionalização acadêmica da Bioética nesses 20 anos no Brasil, este estudo demonstrou que ainda existe um longo caminho a ser percorrido para sua consolidação como disciplina de reflexão teórico-filosófica, em particular, para cumprir a sua missão na pós-graduação stricto sensu, qual seja: capacitar profissionais de diversas áreas com uma visão integral, crítica, autônoma e preparados para atuar no ensino, centros de pesquisas, comitês de éticas e outros setores da sociedade.

Resta, contudo, o maior desafio, que é vencer a carência de profissionais qualificados para os ensinamentos em Bioética, pois, para lidar com todos os temas que envolvem valores, costumes, direitos, limites, responsabilidade social, nos quais a ciência, a vida e a ética interagem entre si, é indispensável, além da qualificação e formação multidisciplinar, considerar entre os atributos do perfil pessoal-profissional inerentes ao processo pedagógico a maturidade intelectual, humana, profissional e acadêmica. 
Como revelou este estudo, apenas 13 (13,53\%) professores possuem formação específica nos graus de especialização, mestrado, doutorado e pós-doutorado nas áreas de concentração em Filosofia, Ética e Bioética, assim como ficou evidente que um número significativo de docentes não possui sequer experiência prática em Comitês de Ética ( $\mathrm{n}=75 ; 78,13 \%$ ).

Espera-se, portanto, que este estudo possa contribuir para o avanço na discussão sobre o atual cenário da inserção da Bioética na pós-graduação stricto sensu no País, já que ficou constatado que o maior desafio está na habilitação de profissionais para o seu ensino. Assim, deseja-se que o presente trabalho sirva tanto como referencial para consulta como de parâmetro de avaliação para novas pesquisas.

\section{REFERÊNCIAS}

1. Reich WT. The word "bioethics": its birth and the legacies of those who shaped it. Kennedy Institute of Ethics Journal. 1994;4(4)):319-35.

2. Pessini L. Bioética: horizonte de esperança para um novo tempo. Mundo da saúde. 1999; 23(5):259-62.

3. Garrafa V. Radiografia bioética de um país - Brasil. Acta bioethica. 2000;6(1):171-75.

4. Ministério da Saúde. Conselho Nacional de Saúde. Comissão Nacional de Ética em Pesquisa (CONEP). As iniciativas institucionais. Cad Ética Pesquisa. 1998; 1(2):14-8.

5. Figueiredo AM. O ensino da Bioética na pós-graduação stricto sensu da área de ciências da saúde no Brasil. Brasília, DF: 2009. Doutorado [Tese] - Universidade de Brasília

6. Monteiro PJC. O ensino da ética/bioética nos cursos de graduação em Enfermagem, Medicina e Odontologia na cidade de Manaus. São Paulo: 2005. Mestrado [Dissertação] - Universidade de São Paulo; 2005.

7. Caramico HJ, Zaher VL, Rosito MMB. Ensino da bioética nas faculdades de medicina do Brasil. Biosthikos. 2007;1(1):76-90.

8. Pessini L, Barchifontaine CP. Bioética e longevidade humana. São Paulo: Loyola; 2006.

9. Vieira PSPG, Neves NMBC. Ética médica e bioética no curso médico sob o olhar dos docentes e discentes. O Mundo da Saúde [periódico na internet]. 2009 [acesso em 20 maio 2010]; 33(1):21-5. Disponível em: http:/ / www.saocamilo-sp.br/pdf/mundo_saude/ 66/21a25.pdf.

10. Siquiera JE, Eisele RL. O ensino da ética no curso de Medicina. Rev Bras Educ Med. 2000;24(1):22-6.

11. Muñoz D, Muñoz DR. O ensino da ética nas faculdades de medicina do Brasil. Rev Bras Educ Med.2003; 27(3):114-24.
12. Guerra MM. Disciplina bioética. Rev Bras Bioética. 2007;3(2):157-69.

13. Coll AN, Nicolescu B, Rosenberg M, Random M, Galvani P, Paul P. Educação e transdisciplinaridade II. Coordenação executiva do CETRANS. São Paulo: TRION; 2002. Anexo 3 - Carta da Transdisciplinaridade.

14. Lavaqui V, Batista IL. Interdisciplinaridade em ensino de ciências e de matemática no ensino médio. Ciênc Educ. 2007;13(3):399-420.

15. Segre M. Ensino da bioética lato sensu. Bioética. ;11(2):57-60.

16. Kipper DJ. Docentes de bioética: critérios de certificação e qualificação. In: Anais do VI Congresso Brasileiro de Bioética. Voz do Iguaçu. São Paulo: Loyola; 2005. p. 20.

17. Garrafa V. Multi-inter-transdiciplinaridade, complexidade e totalidade concreta em bioética. In: Garrafa V, Kottow M, Saada A. Bases conceituais da bioética: enfoque latino-americano. São Paulo: Gaia; 2006. p. 73-85.

18. Zabata A. A prática educativa: como ensinar. Porto Alegre: Artmed; 1998. Reimpressão 2008. p. 13.

19. Batista NA, Silva SHS. O professor de Medicina: conhecimento, experiência e formação. 2 ed. São Paulo: Loyola; 2001.

20. Dantas F, Sousa EG. Ensino da Deontologia, Ética Médica e Bioética nas Escolas Médicas Brasileiras. Rev Bras Educ Med. 2008;32(4):507-14.

21. Demo P. Professor do futuro e reconstrução do conhecimento. 5 ed. Petrópolis: Vozes; 2007.

22. Mello MF, Barros VM, Sommerman A. Introdução. In: Educação e transdisciplinaridade II. Coordenação executiva do CETRANS. São Paulo: Trion; 2002.

23. Masetto MT. Competência pedagógica do professor universitário. São Paulo: Summus; 2003.

24. Rios PA. Compreender e ensinar: por uma docência da melhor qualidade. 7 ed. São Paulo: Cortez; 2008.

\section{CONFLITO DE INTERESSES}

Declarou não haver.

\section{ENDEREÇO PARA CORRESPONDÊNCIA}

Antonio Macena de Figueiredo

Rua Antonio Parreira, n. 15 apto. 1301

Boa Viagem - Niterói

CEP. 24210-320 RJ

E-mail: macenaso@yahoo.com.br 